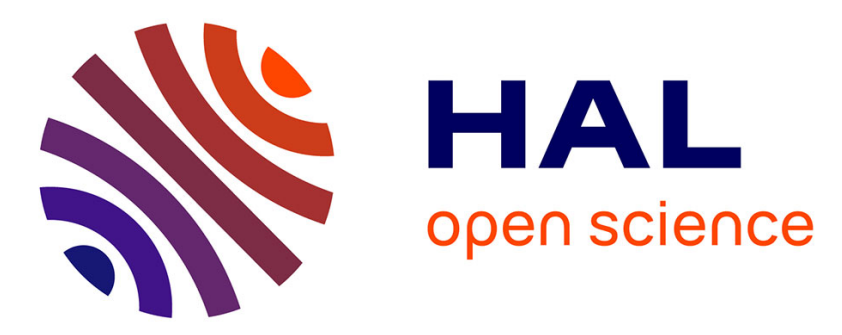

\title{
Interpretation of the Particularities of Lithium-Ion Capacitors and Development of a Simple Circuit Model
}

\author{
Nagham El Ghossein, Ali Sari, Pascal Venet
}

\section{To cite this version:}

Nagham El Ghossein, Ali Sari, Pascal Venet. Interpretation of the Particularities of Lithium-Ion Capacitors and Development of a Simple Circuit Model. VPPC, Oct 2016, Hangzhou, China. 7791712 (5 p.), 10.1109/VPPC.2016.7791712 . hal-01645639

\section{HAL Id: hal-01645639 \\ https://hal.science/hal-01645639}

Submitted on 23 Nov 2017

HAL is a multi-disciplinary open access archive for the deposit and dissemination of scientific research documents, whether they are published or not. The documents may come from teaching and research institutions in France or abroad, or from public or private research centers.
L'archive ouverte pluridisciplinaire HAL, est destinée au dépôt et à la diffusion de documents scientifiques de niveau recherche, publiés ou non, émanant des établissements d'enseignement et de recherche français ou étrangers, des laboratoires publics ou privés. 


\title{
Interpretation of the Particularities of Lithium-Ion Capacitors and Development of a Simple Circuit Model
}

\author{
N. El Ghossein, A. Sari, P. Venet \\ Univ Lyon, Université Lyon 1, \\ AMPERE, UMR CNRS 5005, \\ 69100 Villeurbanne, France
}

\begin{abstract}
The expeditious development of electric vehicles and hybrid electric vehicles relies on using appropriate energy storage systems such as supercapacitors and lithium-ion batteries. The new technology that combines both conventional energy storage systems is the lithium-ion capacitor. The aim of this component is to fill the gaps between supercapacitor's low energy density and lithium-ion battery's low power density. This paper presents the main electrical characteristics, deduced from frequency domain measurements, of such a technology. The nonlinear capacitance evolution of a lithium-ion capacitor cell with respect to the voltage was analyzed based on its physicochemical properties. Moreover, the lithium-ion capacitor was modeled using a simple model derived from the frequency measurements.
\end{abstract}

Keywords - Lithium-ion capacitor; Electrical model; Energy storage; Nonlinear capcitance evolution; Electrochemical behavior

\section{INTRODUCTION}

Automobiles used in people's daily lives produce emissions that are extremely harmful. The cumulative effects of exhaust gas threaten the environment and human life severely. Thus, vehicle electrification becomes inevitable in order to reduce the amount of undesired pollutants generated by the combustion of fossil fuels. The environmentally friendly energy storage systems are integrated into transport facilities in order to struggle against the pollution.

Lithium-ion batteries have proven propitious properties such as high specific energy and high power density compared to other battery types. Among this family of batteries exist many technologies that are related to the positive and negative electrodes' materials: lithium-iron sulphide (FeS), lithiumtitanate (LiTiO/NiMnO2), lithium-iron phosphate (LiFePO4), lithium-ion polymer (LiPo), ... [1]. They are characterized by their low discharge rate and high energy density. Because of their significant energy and power capabilities, they are suitable for several applications such as Plug-in Hybrid Electric Vehicles (PHEV) [2]. For further increase in fuel economy, Electrochemical Double Layer Capacitors (EDLCs), known as supercapacitors, were introduced. They provide a power density higher than that of Lithium-Ion Batteries (LIBs). This is due to their low resistance less than $1 \mathrm{~m} \Omega$. On the other hand, they possess a long cycle life and they have proven a better behavior in negative temperatures than LIBs. However, their energy capabilities are low [3].

Therefore, the search for a hybrid energy storage system that combines the advantages of both technologies had risen during the past years. Several energy management strategies for associating EDLCs with LIBs in one system have been carried out in the field of transportation [4-5]. In terms of power supply, the role of the battery concerned the average power while the EDLC supplied the change in power. This would increase the lifetime of the battery and decrease the cost of the system [6-7].

Instead of using two distinct systems, Lithium-Ion Capacitors (LICs) are the new technology that aims to deliver high energy and high power while assuring a long cycle life. Its composition is inspired from that of EDLCs and LIBs; thus, it provides features intermediate between both systems [8]. Based on the Ragone plot (Fig. 1) describing energy and power densities of energy storage systems present in the market, LICs possess characteristics closer to those of EDLCs. However, their energy densities are higher since their maximum voltage $(3.8 \mathrm{~V})$ is greater than that of EDLCs (usually $2.7 \mathrm{~V})$.

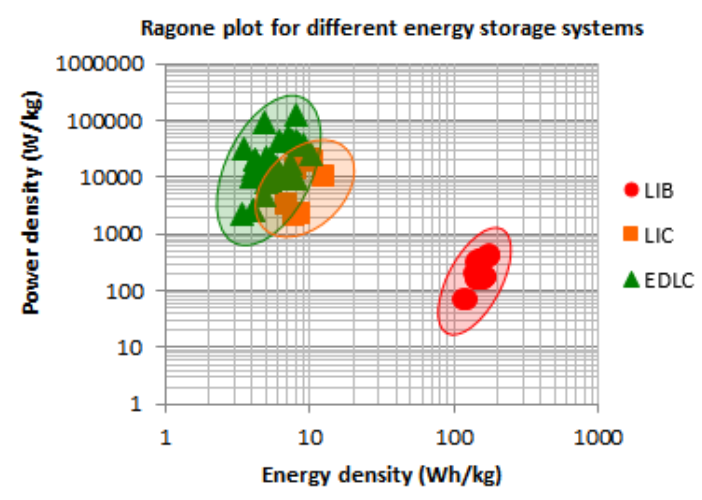

Fig. 1. Ragone plot comparing characteristics of commercial energy storage systems. 
This paper presents in section II the operating principle of a LIC and analyzes its electrical behavior based on data collected from measurements in the frequency domain. In order to simulate this behavior of a LIC, it is modelled using an electrical model in section III.

The tested product is the Ultimo prismatic cell shown in Fig. 2. This LIC is developed by JM Energy and has the properties summarized in Table I.

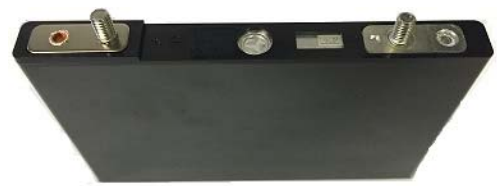

Fig. 2. Ultimo prismatic cell $3300 \mathrm{~F}$.

TABLE I. LIC PROPERTIES

\begin{tabular}{|l|c|}
\hline Voltage range (V) & $2.2-3.8$ \\
\hline Capacity (F) & 3300 \\
\hline Energy density (Wh/kg) & 13 \\
\hline $\begin{array}{l}\text { Equivalent series resistance at } \mathbf{1} \\
\mathbf{k H z}(\mathbf{m} \Omega)\end{array}$ & 0.7 \\
\hline Power density (kW/kg) & 10 \\
\hline Maximum charge current (A) & 125 \\
\hline Maximum discharge current (A) & 360 \\
\hline
\end{tabular}

\section{OPERATING PRINCIPLE AND ELECTRICAL CHARACTERISTICS}

The positive electrode of a LIC is similar to the positive electrode of an EDLC. Similarly, the negative electrode of a LIC is the same as that of the majority of LIBs. Therefore, in order to understand the main electrochemical processes happening in a LIC, it is important to recall the ones taking place in an EDLC and in a LIB as in [9-10].

\section{A. Working Principle}

A commercial LIC cell is composed of a positive electrode of activated carbon and a negative electrode of a carbon material pre-doped with lithium. The pre-lithiation of carbon decreases the electrode's potential in order to increase the cell's overall voltage. There are several methods used for intercalating lithium ions into carbon layers and the level of pre-lithiation has an important impact on the cell specific capacitance and cycle stability [11-12]. Both electrodes are placed in an organic electrolyte containing a lithium salt: $1 \mathrm{M}$ LiPF6 in 1:1 mixture of ethyl carbonate (EC) and dimethyl carbonate (DMC). The same configuration of the electrolyte is usually used in LIBs. A separator between electrodes is employed to isolate the association electronically while allowing the migration of ions.

During the charge from $2.2 \mathrm{~V}$ to $3 \mathrm{~V}$, the cations $L i^{+}$are desorbed from the surface of pores of the activated carbon and intercalated into the carbon layers. From $3 \mathrm{~V}$ to $3.8 \mathrm{~V}$, the anions $P F 6^{-}$are adsorbed on the surface of the activated carbon positive electrode while the cations $\mathrm{Li}^{+}$are further intercalated into the negative electrode of carbon as seen in Fig. 3 [11]. During the discharge, the opposite process happens.

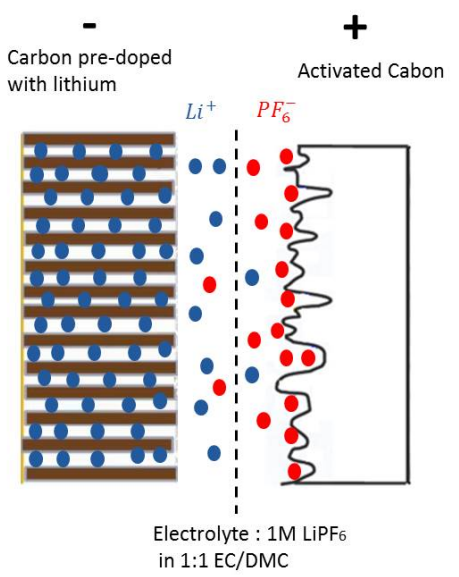

Fig. 3. The composition of the LIC cell at the end of the charge.

Therefore, for a LIC, at the positive electrode a non-faradaic process occurs while at the negative electrode faradaic reactions take place according to the following equation:

$$
x L i^{+}+x e^{-}+6 C \leftrightharpoons L i_{\mathrm{x}} C_{6}
$$

The voltage at the negative electrode barely changes during the charge and the discharge of the cell. Thus, the adsorption and desorption of ions at the surface of the positive electrode have the most significant effect on voltage and capacitance changes of a LIC.

\section{B. Electrical Characteristics}

The performance of LICs was investigated using frequency domain measurements. Impedance data were collected in order to analyze the electrical behavior of this technology.

Galvanostatic Electrochemical Impedance Spectroscopy (GEIS) measurements were applied to a LIC using a sinusoidal current having an amplitude of $5 \mathrm{~A}$ in the frequency range of $10 \mathrm{mHz}$ to $100 \mathrm{kHz}$ at $25^{\circ} \mathrm{C}$. The well-defined protocol in Fig. 4 for the succession of measurements at five voltage values is followed in order to increase the accuracy of the results. The potential of the cell, at which the GEIS is applied, is maintained at a Constant Voltage (CV) for $30 \mathrm{~min}$ before starting the measurement process. In addition, reaching the required voltage at each measuring step is done by charging the LIC using a Constant Current (CC) of $10 \mathrm{~A}$. In order to show the measured complex impedance, Nyquist plots, in Fig. 5, illustrate the opposite of the imaginary part of the impedance with respect to its real part for five voltage values. At high frequencies, the voltage does not have a major influence on the impedance values. However, at low frequencies, both imaginary and real parts of the impedance depend on the voltage. Therefore, in order to investigate furthermore the influence of the cell's potential, additional 


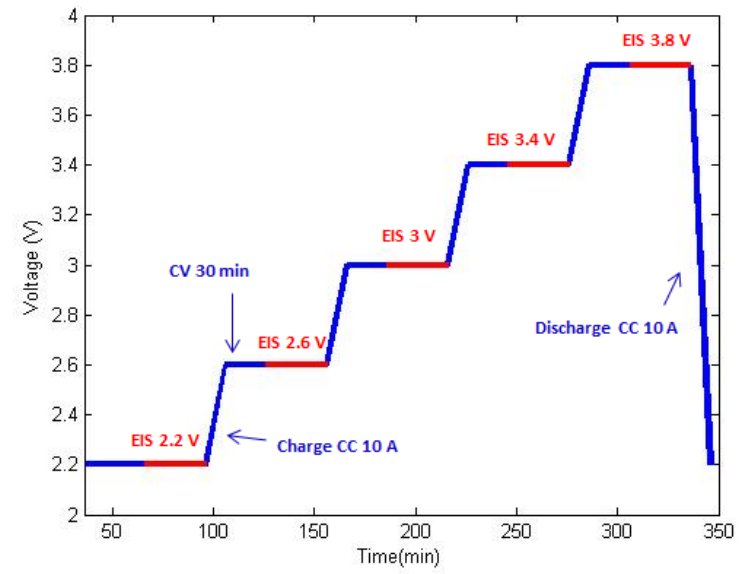

Fig. 4. The protocol followed during the application of GEIS measurements.

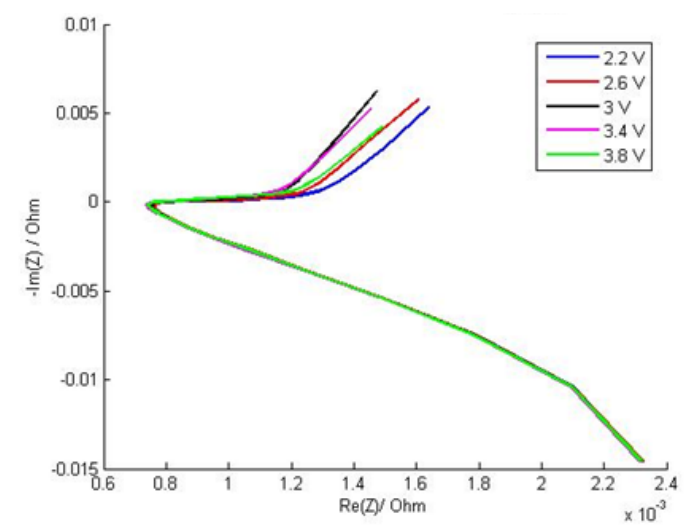

Fig 5. The representation of the measured impedance for five voltage values.

measurements were done for a step voltage of $0.1 \mathrm{~V}$ in the range of 2.2-3.8 $\mathrm{V}$.

Nyquist plots for different cell potentials are illustrated in Fig. 6 at low frequencies. Observing the impedance for different potentials leads to evaluating the changes of the capacity as a function of cell's potentials. Fig. 7 shows the resulting graph of the measured capacity at $10 \mathrm{mHz}$ with respect to the voltage. Considering both electrodes as two capacitances in series, the total capacitance $C_{t}$ of the LIC cell is expressed by:

$$
\frac{1}{C_{t}}=\frac{1}{C^{+}}+\frac{1}{C^{-}}
$$

where, $C^{-}$is the capacitance of the negative electrode and $C^{+}$is the capacitance of the positive electrode. However, the phenomena of the $\mathrm{Li}^{+}$intercalation and deintercalation into carbon layers are very slow compared to the adsorption and desorption of ions at the surface of the activated carbon [13].Therefore, the change in $C_{t}$ is mainly affected by the variation of $C^{+}$if the changes in $C^{-}$are considered negligible.

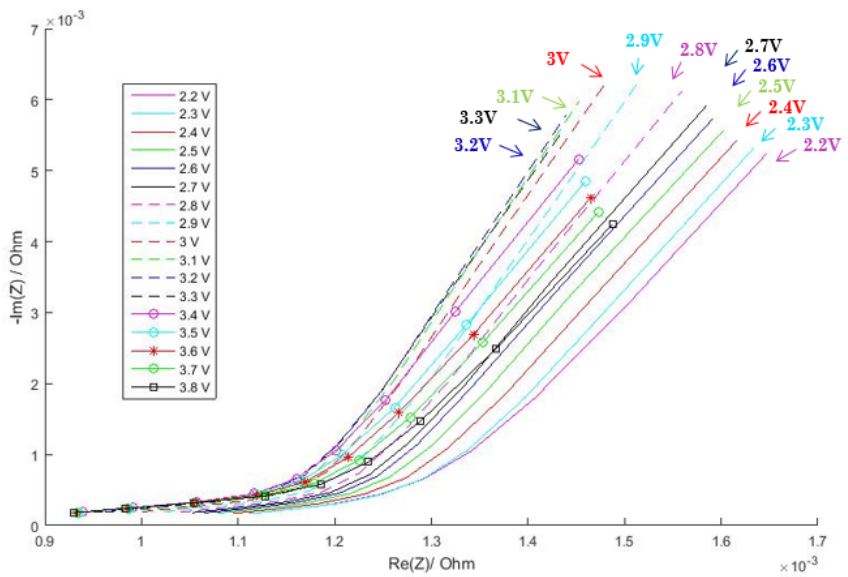

Fig. 6. Comparison of Nyquist plots for different cell potentials at low frequencies $(10 \mathrm{mHz}$ to $1 \mathrm{~Hz})$ at $25^{\circ} \mathrm{C}$.

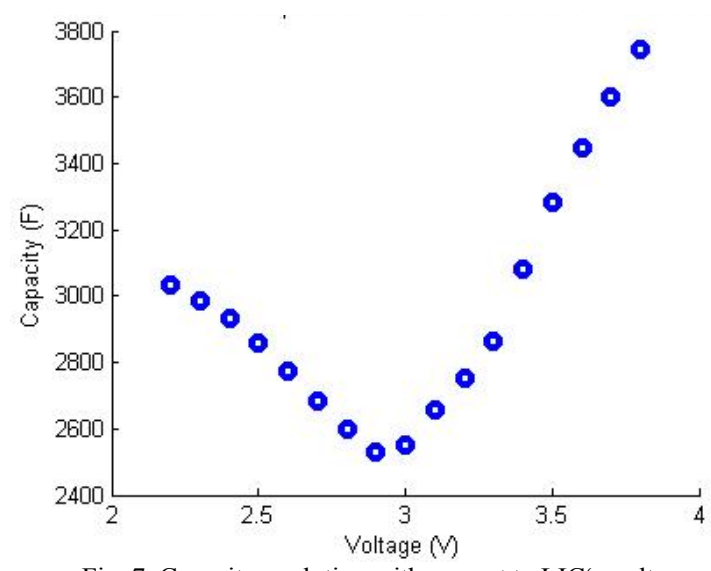

Fig. 7. Capacity evolution with respect to LIC's voltage.

From Fig. 7, one can conclude that while charging the LIC from $2.2 \mathrm{~V}$ to $3 \mathrm{~V}, \mathrm{C}_{\mathrm{t}}$ decreases with voltage increase. According to the working principle explained before, in this range of voltage, the cations $\mathrm{Li}^{+}$leave the surface of the activated carbon thus $\mathrm{C}^{+}$diminishes. This explains the decrease in $C_{t}$. In addition, charging the LIC from $3 \mathrm{~V}$ to $3.8 \mathrm{~V}$ causes the increase of $C_{t}$ which seems also related to the operating principle stating that within this range of voltage the anions are adsorbed on the surface of the positive electrode. Thus, the capacitance of the LIC is increased.

In order to study the effects of high temperatures on the dependence of the capacitance on the cell's voltage, GEIS measurements were done at $40^{\circ} \mathrm{C}$ and $60^{\circ} \mathrm{C}$ for the five potential values used before. The LIC cell was placed in a climatic chamber for 4 hours at the temperature of the test prior to the start of the measurement procedure. Results of the measured capacity at $10 \mathrm{mHz}$ were compared to the values found previously at $25^{\circ} \mathrm{C}$ as seen in Fig. 8 . 


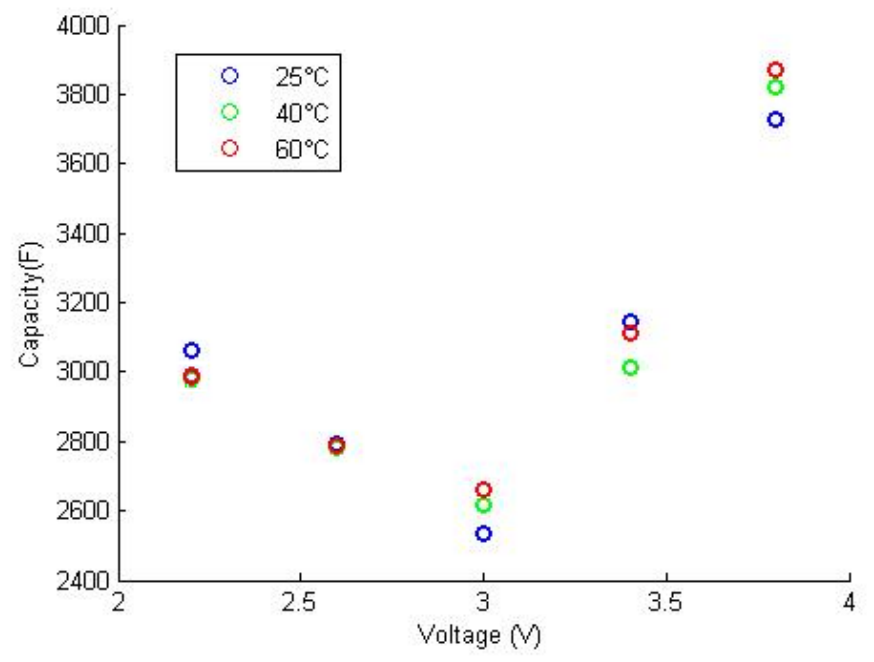

Fig. 8. Capacity evolution with respect to LIC's voltage at 3 different temperatures.

The decrease of the capacity in the voltage window of $2.2 \mathrm{~V}$ to $3 \mathrm{~V}$ and its increase in the voltage window of $3 \mathrm{~V}$ to $3.8 \mathrm{~V}$ are also observed at high temperatures. However, at $2.2 \mathrm{~V}$, the capacitance of the LIC decreases with the temperature increase while at $3 \mathrm{~V}$ and $3.8 \mathrm{~V}$ an increase in the capacitance value is detected. This confirms the particularity of the behavior of the LIC. In fact, in the case of EDLCs, high temperatures induce a small increase in the capacitance for all potentials [14].

\section{ELECTRICAL MODELLING}

For testing the possibility of integrating this technology in applications requiring management systems, it is important to model LIC cells. Several models of LIBs and EDLCs were used to monitor their respective behaviors. The efficiency of the model is related to its ability to describe the performance of the system under different operating conditions.

An EDLC during charge can be modeled by a simple RC circuit. The capacitance of the EDLC is considered to be linear with respect to the voltage. In the case of a LIC, the same model can be used during charge as seen in Fig. 9. However, the capacitance is not assumed to be linear with the voltage according to Fig. 7 .

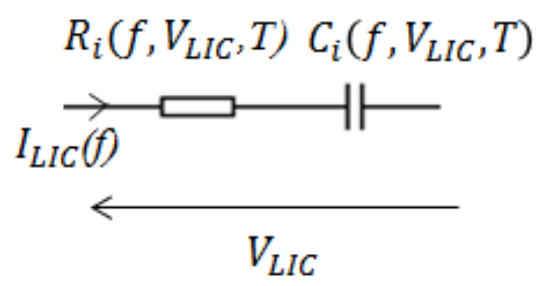

Fig. 9. A simple model that describes the behavior of a LIC.

The impedance of the LIC $Z_{L I C}\left(f, V_{L I C}, T\right)$ depends on the frequency $f$ of the sinusoidal current passing through the cell, on the DC voltage $V_{L I C}$ across the cell and on the operating temperature. It is then described by the following equation:

$$
Z_{L I C}\left(f, V_{L I C}, T\right)=R_{i}\left(f, V_{L I C}, T\right)+\frac{1}{2 \times \pi \times f \times C_{i}\left(f, V_{L I C}, T\right) \times j}
$$

where, $R_{i}\left(f, V_{L I C}, T\right)$ and $C_{i}\left(f, V_{L I C}, T\right)$ are the frequency, voltage and temperature dependent resistance and capacitance of the LIC respectively.

From impedance spectroscopy measurements illustrated in Fig. 6 , one can extract the parameters $R_{i}\left(f, V_{L I C}, T\right)$ and $C_{i}\left(f, V_{L I C}, T\right)$ for different frequencies and voltages using the following equations:

$$
\begin{gathered}
C_{i}\left(f, V_{L I C}, T\right)=\frac{-1}{2 \times \pi \times f \times \operatorname{Im}\left(Z_{L I C}\left(f, V_{L I C}, T\right)\right)} \\
R_{i}\left(f, V_{L I C}, T\right)=\operatorname{Re}\left(Z_{L I C}\left(f, V_{L I C}, T\right)\right)
\end{gathered}
$$

where, $\operatorname{Im}\left(Z_{L I C}\left(f, V_{L I C}, T\right)\right)$ and $\operatorname{Re}\left(Z_{L I C}\left(f, V_{L I C}, T\right)\right)$ are the imaginary and the real parts of the impedance $Z_{L I C}\left(f, V_{L I C}, T\right)$ respectively.

Another simple frequency-independent RC circuit can be considered for describing the behavior of LICs. The resistance would be equal to the resistance of the LIC at the resonant frequency at which the imaginary part of $Z_{L I C}\left(f, V_{L I C}, T\right)$ is equal to zero. For example, at $3.8 \mathrm{~V}$ and at $25^{\circ} \mathrm{C}$, this resistance is equal to $0.7 \mathrm{~m} \Omega$. In addition, the capacitance at $10 \mathrm{mHz}$ would be the best choice for the capacitance value of the circuit model since it is the best to describe real time application of the LIC.

\section{DISCUSSION}

LICs seem as an interesting technology that combines the advantages of EDLCs and LIBs. Its particularity remains in the nonlinear dependence of its capacitance on the voltage. Thus, choosing the optimal operating voltage of the cell must take into account the evolution of its capacitance.

Since the voltage of the pre-lithiated carbon is very low, the cell voltage is approximately equal to the potential of the activated carbon electrode. Therefore, at $3 \mathrm{~V}$, one can conclude that the activated carbon electrode is at its neutral state since its potential is equal to its potential $\mathrm{VS} \mathrm{Li} / \mathrm{Li}^{+}$. This explains the minimum value of the capacitance around $3 \mathrm{~V}$.

\section{CONCLUSION}

The development of hybrid components targets improving the characteristics of energy storage systems. LICs can be employed in high energy and high power applications because of their significant energy and power densities. Their specifications were introduced in this paper using frequency measurements that highlighted the nonlinear dependence of the capacitance on the voltage of the cell. A Physicochemical analysis was conducted in order to interpret this exceptional relationship between the capacitance and the voltage. These 
measurements were also the first step for modeling these cells. The depicted model is very simple and describes the behavior of the LIC during charge. However, further work is being done for improving this model and increasing its complexity so it would better suit the behavior of LICs while providing a high accuracy. Moreover, a model derived from time domain measurements is also under study in order to compare the efficiencies of both modeling methodologies.

\section{REFERENCES}

[1] S. F. Tie and C. W. Tan, "A review of energy sources and energy management system in electric vehicles", Renewable and Sustainable Energy Reviews, vol. 20, pp. 82-102, 2013.

[2] S. Vazquez, S. M. Lukic, E. Galvan, L. G. Franquelo, and J. M. Carrasco, "Energy storage systems for transport and grid applications", IEEE Trans. Ind. Electron., vol. 57, pp. 3881-3895, Dec. 2010.

[3] A. Burke, "Ultracapacitor technologies and application in hybrid and electric vehicles", Int. J. Energy Res., vol. 34, no. 2, pp. 133-151, Feb. 2010

[4] A. Allegre, R. Trigui and A. Bouscayrol, "Different energy management strategies of hybrid energy storage system (HESS) using batteries and supercapacitors for vehicular applications", in Proc. IEEE Veh. Power Propuls. Conf., Sep. 2010, pp. 1-6

[5] J. Cao and A. Emadi, "A new battery/ultra-capacitor hybrid energy storage system for electric, hybrid and plug-in hybrid electric vehicles", in Proc. IEEE Vehicle Power Propulsion Conf., Sep. 2009, pp. 941-946.
[6] R. A. Dougal, S. Liu, and R. E. White, "Power and life extension of battery/ultracapacitor hybrids", IEEE Trans. Comp. Packag. Technol., vol. 25, pp. 120-131, Mar. 2002.

[7] A. Lahyani, A. Sari, I. Lahbib and P. Venet, "Optimal hybridization and amortized cost study of battery/supercapacitors system under pulsed loads", J. Energy Storage, Feb. 2016.

[8] J. Ronsmans and B. Lalande, "Combining energy with power: Lithiumion capacitors", in IEEE Int. Conf. on Electrical Systems for Aircraft, Railway, Ship Propulsion and Road Vehicles, 2015.

[9] R. German, P. Venet, A. Sari, O. Briat, and J.-M. Vinassa, "Improved supercapacitor floating ageing interpretation through multi-pore impedance model parameters evolution", IEEE Trans. Power Electron., vol. 29, pp. 3669-3678, Jul. 2014.

[10] K. Smith, "Electrochemical control of lithium-ion batteries [applications of control]", IEEE Control Syst. Mag., vol. 30, no. 2, pp. 18-25, Apr. 2010.

[11] S. R. Sivakkumar and A. G. Pandolfo, "Evaluation of lithium-ion capacitors assembled with pre-lithiated graphite anode and activated carbon cathode", Electrochim. Acta, vol. 65, pp. 280-287, 2012.

[12] S. Kumagai, T. Ishikawa and Naoki Sawa, "Cycle performance of lithiumion capacitors using graphite negative electrodes at different prelithiation levels", J. Energy Storage, vol. 2, pp. 1-7, 2015.

[13] S.R. Sivakkumar, J.Y. Nerkar and A.G. Pandolfo, "Rate capability of graphite materials as negative electrodes in lithium-ion capacitors", Electrochim. Acta, vol. 55, pp. 3330-3335, 2010.

[14] Y. Diab , P. Venet, H. Gualous and G. Rojat, "Electrical, frequency and thermal measurement and modelling of supercapacitor performance", in Proc. 3rd ESSCAP, 2008. 